\title{
Predicting Point of Collision and Estimating the Ship Movement as Evaluation Method of Collision Risk
}

\author{
Emmy Pratiwi ${ }^{1, a, *}$, Ketut Buda Artana ${ }^{1}$, A.A.B. Dinariyana ${ }^{1}$ and Basuki Widodo ${ }^{2, b}$ \\ ${ }^{1}$ Department of Marine Engineering, PUI Keselamatan Kapal dan Instalasi Laut, Institut Teknologi \\ Sepuluh Nopember Surabaya, Surabaya, Indonesia \\ ${ }^{2}$ Department of Mathematics, Institut Teknologi Sepuluh Nopember, Surabaya, Indonesia \\ a.pratiwi.emmy@gmail.com,b.b_widodo@matematika.its.ac.id \\ *corresponding author
}

Keywords: AIS, linear algorithm, matrix, ship collision, space geometry.

Abstract: Marine traffic safety has been an important research issue in recent years due to high number of maritime accident majorly ship collision. Measuring the collision risk can be useful for navigator to maneuver the ship based on appropriate decision for collision avoidance. The process of collision between vessels can be expressed by predicting the point where the ship would be likely to meet and the collision may occurs using the geometry of the ship's position. This study also utilized the ship trajectory to estimate the future position of the vessel and compared it with the predicted point in geometry calculation result. The collision risk will occur when ships meet in the same position in the same time based on the ship's movement prediction. Thus, the simplest model to evaluate the ship collision risk by using matrices and linear algorithm were performed. In this paper, Automatic Identification System (AIS) data is utilized and linear algorithm is employed to predict the ship movement. This study resulted the possibly position of collision and predicted the new coordinate's position of the ship in t time. The proposed method can be considered as a first step to conduct collision avoidance and to improve navigation of ships in narrow and shallow waterways.

\section{Introduction}

Marine traffic safety has been an important research issue in recent years due to high number of maritime accident majorly ship collision. To improve the safety and reduce the number of ship collision, it is necessary to detect and evaluate the collision risk. Measuring the collision risk can be useful for navigator to maneuver the ship based on appropriate decision for collision avoidance.

When the ship is involved in conflict situation, navigator should maintain the ship to keep it safe. One of the most widely used ways to evaluate conflict situations is using the concept of ship domains. Ship domain is the area around the ship where the navigator must be able to keep it free from other objects such as ships to remain safe and convenient for sailing ships [1], [2]. The concept of ship domain was first introduced by in 1971 [3]. Other common domain ship models provided by Goodwin and Coldwell [4], [5]. Not all the encounter situation resulted in collision, therefore the ships involved in conflict encounter situations will be evaluated to determine the ship collision risk. 
The process of collisions between two vessels can be analyzed in two ways, namely based on relative motion and true motion [6]. Closest point of approach (CPA) is a value in the collision process associated with relative motion. CPA related to distance and time are the conventional collision risk evaluation method. CPA indicates the positions at which two dynamically moving objects reach their closest possible distance. However, it is not the same as the closest distance between the lines. The distance between the points must be calculated at the same moment in time [7]. As shown in Fig. 1, DCPA and TCPA can be obtained by geometric calculation.

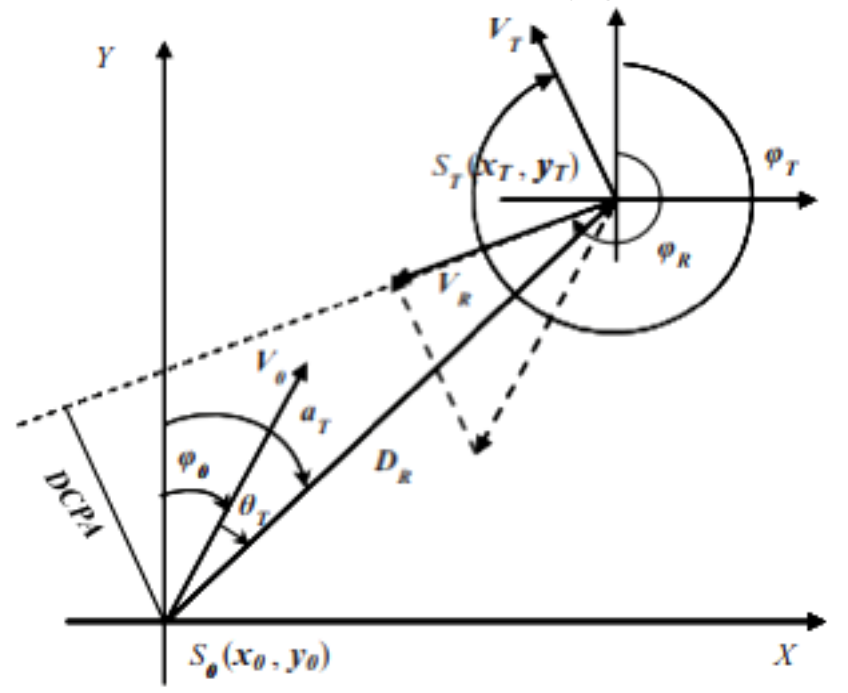

Figure 1: Geometric calculation of DCPA and TCPA [8]

Imazu [6] mentioned that collision risk evaluation method by using CPA has several problems for collision avoidance in congested area. To evaluate the encounter situation, the CPA was compared with the assumed safe distance [9]. The collision avoidance action can be successful if CPA is larger than a certain value [10]. Many authors have conducted studies with the aim of determining the safe distance for CPA. The CPA depends on several factors but the primary are ship maneuverability, meteorological and oceanological conditions, and the area of navigation [11]. Therefore, the CPA may differ for certain area depending on each conditions.

The second way is namely as Point of Predicted Collision (PPC). PPC is a meeting point between two vessels at the same place and time from the starting point of each ship. Two moving vessels arrive at the same place at the same time from their own position. This is related to the true motion [6]. Galor [9] mentioned that PPC has better quality in ship encounter assessment because the evaluation is conducted in the term of possible collision and directly performing avoiding maneuver in relation to all the observed ships.

This study adopted PPC as an early way of collision avoidance. The purpose of this study is to predict the point at which the ships will be likely to meet and the collision may occur based on true motion of the vessel in the simple and complex encounter situation involving more than two vessels.

Moreover, the collision risk can be determined by predicting the movement of ships in the future time. In this paper, authors applied the simplest model to describe the ship movement called a linear algorithm. It is assumed that the ships are moving along rather linear path because most of the ships are moving by the shortest route [12]. Automatic Identification System (AIS) data was utilized to predict the ship movement. This study compared those two methods to find the position of collision in narrow and shallow waterways. The proposed method can be considered as a first step to conduct collision avoidance and to improve navigation of ships in narrow and shallow waterways. 


\section{Methodology}

\subsection{Predicting Collision Point between Two Vessels}

To determine the possibility of ship collision, the first step is predicting the collision point that will occur based on the geometry of the ship's position. The method proposed by Chong had been adopted and developed in this study [13].

When two moving objects toward to certain direction could meet in one point (Fig. 2). The intersection as the point of collision is the position in [ix,iy]. Using the matrix form, [ix,iy] can be defined by following steps:

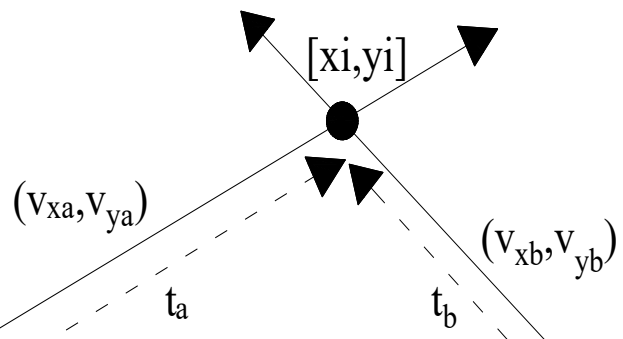

$(\mathrm{a}, \mathrm{b})$

$(\mathrm{c}, \mathrm{d})$

Figure 2: The intersection between two lines [13]

$[a, b]$ and $[c, d]$ is the starting position of each own ships (called vessel A and Vessel B). Vessel A moves with the velocity as (vxa,vya) and vessel B moves with the velocity as (vxb,vyb). ta and tb are time of the collision for each vessel, and only they are unknown. Firstly, time to collision will be calculated by using this formula:

Intersection at [ix,iy]

$$
\begin{aligned}
& {[a, b]+t_{a}\left[v_{x a}, v_{y b}\right]=[i x, i y]} \\
& {[c, d]+t_{b}\left[v_{x b}, v_{y b}\right]=[i x, i y]} \\
& a+t_{a} v_{x a}=c+t_{b} v_{x b} \\
& a-c=t_{b} v_{x b}-t_{a} v_{x a} \\
& b+t_{a} v_{y a}=d+t_{b} v_{y b} \\
& b-d=t_{b} v_{y b}-t_{a} v_{y a}
\end{aligned}
$$

Those two equations can be rewrite in matrix form:

$$
\left(\begin{array}{l}
a-c \\
b-d
\end{array}\right)=\left(\begin{array}{ll}
v_{x b} & -v_{x a} \\
v_{y b} & -v_{y a}
\end{array}\right)\left(\begin{array}{l}
t_{b} \\
t_{a}
\end{array}\right)
$$

$t_{a}$ and $t_{b}$ can be calculated by using inverse matrix of velocity and multiply with starting positions matrix as following steps below: 


$$
\begin{gathered}
S=\left(\begin{array}{c}
a-c \\
b-d
\end{array}\right) V=\left(\begin{array}{ll}
v_{x b} & -v_{x a} \\
v_{y b} & -v_{y a}
\end{array}\right) t=\left(\begin{array}{c}
t_{b} \\
t_{a}
\end{array}\right) \\
V t=S \\
V^{-1} V t=V^{-1} S \\
t=V^{-1} S
\end{gathered}
$$

$\mathrm{V}-1$ is the inverse of $\mathrm{V}$ and $\mathrm{VV}-1$ is identity matrix.

After knowing $\mathrm{t}$ the time of the collision, the $\mathrm{x}$ coordinates and the $\mathrm{y}$ coordinates will be equal [14], so the intersection point can be obtained.

$$
\begin{aligned}
& {[i x, i y]=[a, b]+t_{a}\left[v_{x a}, v_{y a}\right]} \\
& i x=a+t_{a} v_{x a} \\
& i y=b+t_{a} v_{y a} \\
& \text { or } \\
& {[i x, i y]=[c, d]+t_{b}\left[v_{x b}, v_{y b}\right]} \\
& i x=c+t_{b} v_{x b} \\
& i y=d+t_{b} v_{y b}
\end{aligned}
$$

\subsection{Linear Algorithms for Ship Movement Prediction}

Automatic Identification System (AIS) is utilized in this study to provide data and information about the ship such as:

- Speed over ground (SOG)

- The direction of movement COG (Course Over Ground)

- The position coordinates

Firstly, speed over ground (SOG) obtained from AIS in knots should be converted to $\mathrm{m} / \mathrm{s}$ ( $\mathrm{sog}$ ) by following equation [12]:

$$
\operatorname{sog}=0.514444 \times S O G
$$

Then the distance of ship movement (s) in time t can be calculated by [12]:

$$
s=\operatorname{sog} \times t
$$

The ship movement in $\mathrm{x}$ and $\mathrm{y}$ axis (namely $\Delta \mathrm{x}$ and $\Delta \mathrm{y}$ ) must be calculated by taking into account the course COG [12]:

$$
\begin{aligned}
& \Delta x=s \times \sin (C O G \times \pi / 180) \\
& \Delta y=s \times \cos (C O G \times \pi / 180)
\end{aligned}
$$

From AIS data, the $\mathrm{x}$ and $\mathrm{y}$ shows the coordinate's position of the ship in previous moment can be known. Finally, new coordinates of the ships are obtained [12]: 


$$
\begin{aligned}
& x^{\prime}=x+\Delta x \\
& y^{\prime}=y+\Delta y
\end{aligned}
$$

\section{Result and Discussion}

\subsection{Study Case for Predicting Point of Collision in Madura Strait}

The methodology applied for ships passing in Surabaya West Access Channel (SWAC) located in Madura Strait. SWAC is one of crowded shipping channel with high marine traffic density, therefore it is narrow and shallow waterways. In the initial case study involving two ships. Ship data such as speed, position and angle of ship heading were obtained through an AIS receiver which installed in ITS as shown in the following TABLE I.

Table 1: Ships Data

\begin{tabular}{|l|c|c|}
\hline & Ship A & Ship B \\
\hline Speed & $7.408 \mathrm{~km} /$ jam & $7.408 \mathrm{~km} / \mathrm{jam}$ \\
\hline Latitude & $-7.10661(-793140.48)$ & $-7.10647(-793124.78)$ \\
\hline Longitude & $112.65678(12540905.4)$ & $112.65761(12540987.78)$ \\
\hline Heading & $7^{\circ}$ & $50^{\circ}$ \\
\hline
\end{tabular}

The point where the vessel could meet is the intersection between the two vessel trajectories if the vessel remains its speed at a constant velocity and constant heading.

Based on (1), (2) and (3) then the matrix that had been arranged into (4).

$$
\left(\begin{array}{l}
a-c \\
b-d
\end{array}\right)=\left(\begin{array}{ll}
v_{x b} & -v_{x a} \\
v_{y b} & -v_{y a}
\end{array}\right)\left(\begin{array}{c}
t_{b} \\
t_{a}
\end{array}\right)
$$

The velocity of the vessel in the matrix is the velocity of the vessel against the $\mathrm{x}$ coordinates and the y coordinates affected by the ship's direction. ta and tb could be calculated by the inverse matrix of the velocity and multiplied by the initial position matrix using (6).

From the calculation result, ta and tb were not equal so that ship A and B would not meet at the collision point. As explained previously, PPC is a meeting point between two vessels at the same place and time from the starting point of each ship. Two moving ships would collide if arriving at the same place at the same time from their own position. After the collision time ( $t)$ was known, the $\mathrm{x}$ and $\mathrm{y}$ coordinates for both vessels would be equal, so the point of collision could be obtained as follow [14].

$$
\begin{gathered}
{[i x, i y]=[a, b]+t_{a}\left[v_{x a}, v_{y a}\right]} \\
i x=a+t_{a} v_{x a}=12541000 \\
i y=b+t_{a} v_{y a}=-793150
\end{gathered}
$$

Calculations performed by utilizing MATLAB R2013a can be seen on Fig. 3. It means that the position in $(\mathrm{x}, \mathrm{y})$ coordinates in this case is not the point of collision hence both ships will not reach the point at the same time. If ta and tb are same value, so two ship's destination is same, then they will collide. 


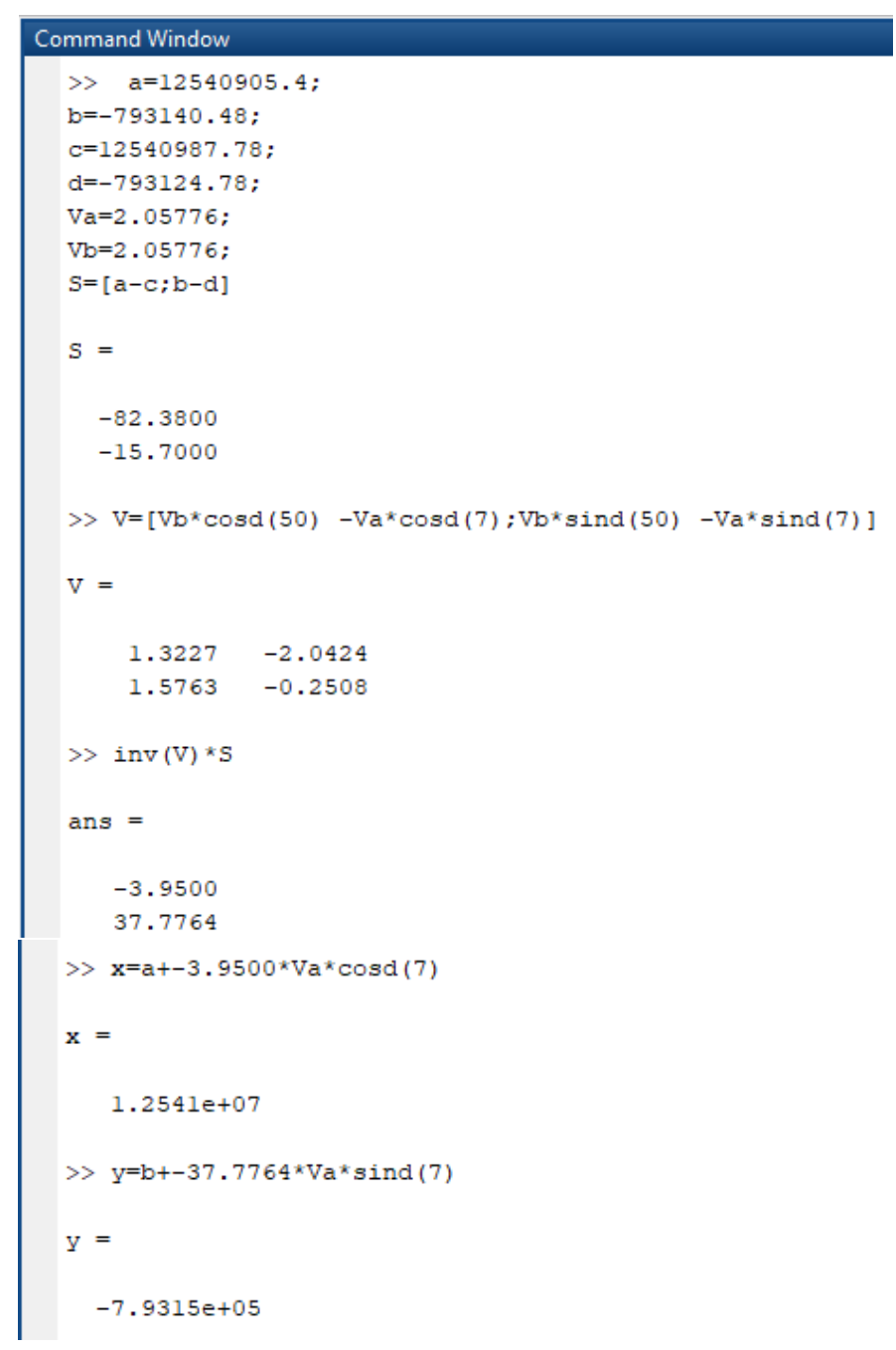

Figure 3: Calculation using MATLAB

\subsection{Ship Movement Predictions}

The position of the ships where the collision may occur was also performed by predicting the ship movement. The method for ship movement prediction is adapted from linear algorithm proposed by Czapiewska and Sadowski [12]. Basically, Czapiewska and Sadowski [12] used the method to decrease the amount of stored data due to recorded trajectories for each vessel gathered only from AIS system is huge. Therefore, the linear algorithm is modified to solve the problems in this study which is determining the ships collision position.

For comparative analysis were used only the same vessel data with study case for predicting point of collision in Madura Strait. In the previous matrices, $t$ is unknown so it should be calculated before measuring the point of collision. However, $t$ time in linear algorithm was determined as an input for calculating the distance of ship movement (s). Actually, this is such a simulation by inputting the various $t$ to find out on what time $(t)$ the ships have the same position so it can be concluded that at the position the ship will probably collide. The steps of calculation for ship movement prediction were conducted according to (9) to (15).

Firstly, the position of the ship should be transformed from WGS - 84 coordinates into Cartesian coordinate system and the speed given in knots ( $\mathrm{SOG}$ ) converted to $\mathrm{m} / \mathrm{s}$ ( $\mathrm{sog}$ ). The $\mathrm{x}$ and $\mathrm{y}$ coordinates of the object in previous moment could be known from AIS system. 
The example calculation using the equation on the linear algorithm to obtain the new position of the ship is as TABLE II follows. Compared with the method for predicting point of collision, this method resulted the new coordinates of the ship in same t time. It indicates that if the new estimated positions among the ships are same, the collision will definitely occur. While the new coordinate positions of the ships resulting in PPC calculation are only the collision location if the ships reach the point at the same time.

Table 2: The Example Calculation Using Linear Algorithm to Obtain The New Position of The Ship

\begin{tabular}{cccccccccc}
\hline SOG $(\mathbf{m} / \mathbf{s})$ & $\mathbf{t}(\mathbf{s})$ & $\mathbf{s}$ & $\mathbf{C O G}$ & $\mathbf{x}$ & $\mathbf{y}$ & $\boldsymbol{\Delta x}$ & $\Delta \mathbf{y}$ & $\mathbf{x}^{\prime}$ & $\mathbf{y}^{\prime}$ \\
\hline 2.057776 & 3.95 & $8 \mathrm{E}-05$ & 293.9 & 12540905.400 & -793140.48 & -7.439791242 & 3.273742294 & 12540897.960 & -793137.206 \\
2.057776 & 37.776 & $4 \mathrm{E}-05$ & 296.8 & 12540987.78 & -793124.78 & -69.476556602 & 34.86642845 & 12540918.303 & -793089.914 \\
\hline
\end{tabular}

\section{Conclusions}

This paper presents the simplest model to evaluate the ship collision risk by using matrices and linear algorithm. Those two methods used different approach even though showing the same results. Predicting point of collision was calculated based on true motion of the ships. The collision risk of two moving vessels could be evaluated by predicting where the point of ships in the same time from each own position. Matrices as conventional and simple method could be used to determine the possibly coordinate position of PPC. Another method that was linear algorithm for ship movement predictions also shows the new coordinate's position of the ship in $t$ time.

The approach taken in this study is deterministic. Hence, this paper still has lacks because it has not considered the effect of the ship shape, trajectory uncertainty and environmental disturbances. They should be taken into account in further research to improve the current model. In addition, it is necessary to present the visual simulation of ship collision process to ensure that the model is applicable and as validation rather than verified by other method. Nevertheless, the proposed method can be considered as a first step to conduct collision avoidance and to improve navigation of ships in narrow and shallow waterways.

\section{Acknowledgements}

The authors are thankful the Ministry of Research, Technology, and Higher Education of Indonesia for funding the research through Doctoral Program Master's Degree Superior (PMDSU) Scholarship.

\section{References}

[1] S. J. Chang, D. T. Hsiao, and W. C. Wang, “AIS-based delineation and interpretation of ship domain models, " in OCEANS 2014 - TAIPEI, 2014, pp. 1-6.

[2] Z. Pietrzykowski, “Ship's Fuzzy Domain-a Criterion for Navigational Safety in Narrow Fairways, ” J. Navig., vol. 61, no. 3, pp. 499-514, 2008.

[3] Y. Fujii and K. Tanaka, "Traffic capacity," J. Navig., vol. 24, no. 4, pp. 543-552, 1971.

[4] E. M. Goodwin, “A statistical study of ship domains,” J. Navig., vol. 28, no. 3, pp. 328-344, 1975.

[5] T. G. Coldwell, "Marine traffic behaviour in restricted waters," J. Navig., vol. 36, no. 3, pp. 430-444, 1983.

[6] H. Imazu, "Evaluation Method of Collision Risk by Using True Motion,” TransNav, Int. J. Mar. Navig. Saf. Sea Transp., vol. 11, no. 1, pp. 65-70, 2017.

[7] D. Sunday, “Distance between 3D Lines \& Segments,” 2012. [Online]. Available: http://geomalgorithms.com/a07distance.html.

[8] L. Gang, Y. Wang, Y. Sun, and L. Zhou, "Estimation of vessel collision risk index based on support vector machine," vol. 8, no. 11, pp. 1-10, 2016. 
[9] W. Galor, “An assessment of ship encounter situations based on predicted points of collision,” Zesz. Nauk. Morska w Szczecinie, no. 46 (118), pp. 82-87, 2016.

[10]J. M. Mou, C. van der Tak, and H. Ligteringen, "Study on collision avoidance in busy waterways by using AIS data," Ocean Eng., vol. 37, no. 5-6, pp. 483-490, 2010.

[11]S. Vujičić, Đ. Mohović, and R. Mohović, “A Model of Determining the Closest Point of Approach Between Ships on the Open Sea," PROMET-Traffic\&Transportation, vol. 29, no. 2, pp. 225-232, 2017.

[12]A. Czapiewska and J. Sadowski, “Algorithms for Ship Movement Prediction for Location Data Compression," TransNav Int. J. Mar. Navig. Saf. Sea Transp., vol. 9, 2015.

[13]K. S. Chong, "Predicting Collision Points With Math in AS3," 2012. [Online]. Available: https://code.tutsplus.com/tutorials/predicting-collision-points-with-math-in-as3--active-11218.

[14]Jbriggs444, "Find the point of collision," 2015. [Online]. Available: https://www.physicsforums.com/threads/findthe-point-of-collision.814621/. [Accessed: 11-Nov-2017]. 